\title{
JURISPRUDENCIA AMBIENTAL EN GALICIA (SEGUNDO SEMESTRE 2018)
}

\author{
María del Carmen Rodríguez Martín-Retortillo \\ Profesora interina e investigadora del Área de Derecho Administrativo \\ Universidade da Coruña
}


Sumario: 1. Introducción. 2. Aspectos relacionados con la Autorización Ambiental Integrada al hilo de las sentencias 260/2018, de 31 de mayo y 370/2018, de 28 de junio (ambas de la Sección Segunda de la Sala de lo Contencioso-Administrativo del Tribunal Superior de Justicia de Galicia). 3. Cuestiones relativas a la evaluación ambiental estratégica a propósito de las sentencias 239/2018 de 31 de mayo y 228/2018, de 7 de junio (ambas de la Sección Segunda de la Sala de lo Contencioso-Administrativo del Tribunal Superior de Justicia de Galicia).

\section{INTRODUCCIÓN}

Las sentencias del Tribunal Superior de Justicia de Galicia contenidas en esta crónica se pueden estructurar en 2 grupos:

- El primero relativo a aspectos relacionados con la Autorización Ambiental Integrada al hilo de 2 sentencias de la Sección Segunda de la Sala de lo Contencioso-Administrativo del Tribunal Superior de Justicia de Galicia (la 260/2018, de 31 de mayo y la 370/2018, de 28 de junio).

- El segundo sobre cuestiones relativas a la evaluación ambiental estratégica a propósito de 2 sentencias de la Sección Segunda de la Sala de lo ContenciosoAdministrativo del Tribunal Superior de Justicia de Galicia (la 239/2018 de 31 de mayo y la 228/2018, de 7 de junio).

\section{ASPECTOS RELACIONADOS CON LA AUTORIZACIÓN AMBIENTAL INTEGRADA AL HILO DE LAS SENTENCIAS 260/2018, DE 31 DE MAYO Y 370/2018, DE 28 DE JUNIO (AMBAS DE LA SECCIÓN SEGUNDA DE LA SALA DE LO CONTENCIOSO-ADMINISTRATIVO DEL TRIBUNAL SUPERIOR DE JUSTICIA DE GALICIA).}

La primera sentencia objeto de análisis es la 260/2018, de 31 de mayo, de la Sección Segunda de la Sala de lo Contencioso-Administrativo del Tribunal Superior de Justicia de Galicia, que resuelve el recurso presentado por "A" contra el acuerdo de 14 de marzo de 2017 de la Consellería de Medio Ambiente e Ordenación do Territorio.

El Fundamento Jurídico Primero recuerda que el acuerdo impugnado rechaza el recurso de reposición de "A" contra la sanción de 60.000 euros, clausura temporal total de la instalación y cese de la actividad.

El 28 de abril de 2008 se le otorgó a la recurrente la autorización ambiental integrada, que fue anulada por la sentencia del Tribunal Superior de Justicia de Galicia de 15 de febrero de 2011 (confirmada por la sentencia del Tribunal Supremo de 27 de junio de 2014). 
Asimismo, cabe aludir a la Resolución de la Consellería de 22 de julio de 2015 anulando el acuerdo de 16 de mayo de 2013 de renovación de la autorización ambiental, destacando que se interpuso recurso y solicitud de suspensión.

En el Fundamento Jurídico Segundo la parte recurrente argumenta que el Tribunal Supremo rechazó la casación y añade que no procedía el expediente sancionador debido a que no existía ningún requerimiento expreso de cese de actividad, ya que a la comunicación de 24 de agosto de 2015 no le confiere ese carácter, alegando además que la licencia de actividad le faculta para continuar trabajando y que se encuentra en trámite una nueva autorización ambiental integrada, sin que la actividad desarrollada genere ningún riesgo.

Posteriormente en este Fundamento se aclara que el expediente sancionador comenzó y finalizó antes del pronunciamiento del Tribunal Superior de Justicia de Galicia de la petición de suspensión del acuerdo de anulación de la renovación de la autorización ambiental integrada. De ello se deriva que cuando la Administración resuelve el expediente sancionador por la comisión de una infracción de carácter grave contemplada en el Artículo 30.3.a) de la Ley 16/2002 (ejercicio de la actividad sin autorización ambiental) el Tribunal Superior de Justicia de Galicia todavía no se pronunció acerca de la petición de suspensión de la decisión de anular la renovación de la autorización.

Por todo lo expuesto el recurso resulta estimado dado que la Administración comenzó su actuación cuando no tenía potestad para hacerlo, sin efectuar condena en costas, tal y como se recoge expresamente en el Fundamento Jurídico Tercero.

La segunda sentencia a tratar es la $370 / 2018$, de 28 de junio, de la Sección Segunda de la Sala de lo Contencioso-administrativo del Tribunal Superior de Justicia de Galicia, que según recuerda su Fundamento Jurídico Primero resuelve el recurso interpuesto en nombre y representación del Concello de Pontevedra, contra la desestimación presunta del requerimiento de anulación de la Resolución de 22 de agosto de 2016 dictada por la Consellería de Medio Ambiente e Ordenación do Territorio, por la cual se modificó el plazo de vigencia de la autorización ambiental integrada otorgada a "E" "para la 
producción de productos químicos de la industria cloro-alcalí por electrolisis hasta el 11 de diciembre de 2017".

Es parte demandada la Xunta de Galicia y codemandada "E".

Su Fundamento Jurídico Segundo contiene los fundamentos de la impugnación del Ayuntamiento de Pontevedra, mientras que el Tercero recoge los fundamentos de la oposición de la Xunta de Galicia.

El Ayuntamiento se basa en que en el expediente se omitió el trámite de audiencia, que resulta obligado de conformidad con la Ley 16/2002 de Prevención y Control Integral de la Contaminación, prescindiendo de todos los informes y controles exigidos en el Artículo 25 de dicha Ley, que "contrariamente a lo que mantiene la resolución recurrida, lo que impone es que en el plazo de 4 años pueda exigirse la implantación de las mejoras técnicas pero no que pueda ampliarse la autorización, por lo que, después de tachar de poco meditada la interpretación realizada en la resolución recurrida del Art. 25 de la Ley 16/2002, termina señalando que la omisión de trámites esenciales del procedimiento determinan la nulidad del acto recurrido al dictarse prescindiendo total y absolutamente del procedimiento legalmente establecido o, subsidiariamente, su anulación".

La Letrada de la Xunta de Galicia, por su parte, "defendió la regularidad de la resolución recurrida señalando que el Ayuntamiento de Pontevedra se equivoca al señalar la naturaleza y el alcance de la resolución que impugna manteniendo que a raíz de la modificación operada por la Ley 5/2013 el régimen de vigencia de las Autorizaciones Ambientales Integradas pasa a ser indefinido", y añade que "la resolución no fue fruto de una modificación de la autorización sino la antesala de su revisión (que se inició el 21/10/2016)" y concluye que el trámite de audiencia está fuera de lugar y por ello insta la desestimación del recurso.

El Fundamento Jurídico Cuarto trata sobre la contestación a la demanda de "E" y recuerda que "con arreglo a la modificación operada por la Ley 5/2013 se suprimió el plazo de vigencia de las Autorizaciones Ambientales Integradas 
pasando a un régimen de revisión y actualización a las mejoras técnicas disponibles, por lo que publicadas en el Diario Oficial de la UE el 11 de diciembre de 2013, las conclusiones sobre la producción de cloro-álcali que determinaron la necesidad de desmantelar la planta por la utilización de celdas de mercurio, acordándose en la resolución recurrida acomodar el plazo de la autorización al máximo previsto conforme a la Directiva 2010/75/UE a 11 de diciembre de 2017, coincidiendo con los 4 años de la publicación de las Conclusiones sobre la mejor técnica disponible, fundamenta su posición en que la resolución recurrida no puede identificarse con una revisión ni una modificación de la autorización porque no afecta a ninguno de los condicionantes técnicos y ambientales recogidos en la misma sino que simplemente se ha adecuado al plazo máximo legal", añadiendo que "la adaptación al plazo máximo previsto en la Autorización Ambiental Integrada para finalizar la utilización de las celdas de mercurio resulta ajustada a la legalidad, sin que pueda entenderse que se haya renovado o prorrogado el plazo de vigencia, sino que simplemente se ha reconocido el plazo contemplado en las conclusiones acerca de la mejor técnica disponible para desmantelar las celdas de mercurio que emplea".

El Fundamento Jurídico Quinto repasa los antecedentes de la resolución recurrida y el Sexto analiza el sentido de la modificación de la Ley de prevención y control integral de la contaminación y comienza afirmando que "con la modificación de la Ley 5/2013, de 11 de junio, por la que se modifican la Ley 16/2002, de 1 de julio, de prevención y control integrados de la contaminación y la Ley 22/2011, de 28 de julio, de residuos y suelos contaminados, ya no es preciso que los titulares de una autorización ambiental integrada interesen periódicamente su renovación, sino que es la administración la que a través de su revisión debe velar porque las actividades contaminantes respeten la mejor técnica disponible para minimizar los impactos medioambientales".

La sentencia aclara sin embargo que "una cosa es que la administración deba proceder a la revisión de las autorizaciones dentro de los 4 años siguientes a la publicación de la decisión de la Comisión y otra, bien distinta por cierto, que la administración prolongue la vigencia de la autorización ambiental concedida 
hasta el plazo máximo en la que debería proceder a la revisión, máxime cuando se admite que la técnica empleada -producción de cloro mediante celdas de mercurio- no se adapta a las admisibles y, en su caso, conforme al Art. 25.2 esas revisiones, a tramitar por el procedimiento simplificado, no darían derecho a indemnización (...)".

Finalmente se estima el recurso contra la desestimación presunta del requerimiento de anulación de la Resolución de 22 de agosto de 2016 dictada por la Consellería de Medio Ambiente e Ordenación do Territorio, por la cual se modificó el plazo de vigencia de la autorización ambiental integrada otorgada a "E" para la producción de productos químicos de la industria cloro-alcalí por electrolisis hasta el 11 de diciembre de 2017, decretando su nulidad, con imposición de costas a la Xunta de Galicia, pero limitadas a la cantidad máxima de $1.500 €$.

\section{CUESTIONES RELATIVAS A LA EVALUACIÓN AMBIENTAL} ESTRATÉGICA A PROPÓSITO DE LAS SENTENCIAS 239/2018 DE 31 DE MAYO Y 228/2018, DE 7 DE JUNIO (AMBAS DE LA SECCIÓN SEGUNDA DE LA SALA DE LO CONTENCIOSO-ADMINISTRATIVO DEL TRIBUNAL SUPERIOR DE JUSTICIA DE GALICIA).

La primera sentencia a tratar es la 239/2018, de 31 de mayo, de la Sección Segunda de la Sala de lo Contencioso-administrativo del Tribunal Superior de Justicia de Galicia, que resuelve el recurso interpuesto en nombre y representación de "B" contra la Orden de 11 de abril de 2016, de aprobación del Plan General de Ordenación Municipal de Muxía, siendo parte demandada la Consellería de Medio Ambiente y Ordenación del Territorio y codemandada el Concello de Muxía.

Como recuerda su Fundamento Jurídico Primero, el objeto del recurso se circunscribe a la Orden de 11 de abril de 2016, de aprobación del Plan General de Ordenación Municipal de Muxía.

De forma principal persigue la anulación total del citado plan por no haberse sometido a evaluación ambiental, y de forma subsidiaria se discute la clasificación urbanística de parte de la parcela (clasificada como suelo rústico de protección agropecuaria cuando en el planeamiento revisado figuraban clasificados los terrenos como suelo de núcleo rural). De este fundamento 
cabe destacar también que en la orden de aprobación se alude, por lo que respecta a la evaluación ambiental estratégica, a que la Secretaria General de Calidad y Evaluación ambiental resolvió el 24 de septiembre de 2014 declarar la inviabilidad de someter al procedimiento de evaluación ambiental estratégica el PGOM.

El Fundamento Jurídico Segundo analiza la fundamentación jurídica de la demanda, examinando la nulidad del Plan General de Ordenación Municipal de Muxía por no haberse sometido al procedimiento de evaluación ambiental estratégica.

Alude a una serie de preceptos: al Artículo 13 de la Directiva 2001/42/CE en relación con su Artículo 3, que establecen la obligación de someter al procedimiento de evaluación ambiental estratégica los planes y programas "que puedan tener efectos significativos sobre el medio ambiente", a la Ley 21/2013, a los artículos 6 y 7, al Artículo 5.b) de la Ley 6/2007 y al Artículo 45.4 de la Ley 42/2007.

Asimismo, argumenta que la urgencia no es una excusa y que no existe justificación para no someterlo a la evaluación ambiental e invoca las sentencias del Tribunal Supremo de 23 de diciembre de 2014 y de 10 de noviembre de 2015, así como que el territorio de Muxía se encuentra incluido en parte en la Red Natura.

También se refiere a los artículos 84.4 y 86.1.g) de la LOUGA y 3, 4, 7 y DT 1a de la Ley 9/2006 y llega a la conclusión tras traer a colación la Disposición Transitoria Primera de la Ley 21/2013 de Evaluación Ambiental que la normativa que resulta de aplicación en este supuesto es la Ley 9/2006, de 28 de abril, sobre evaluación de los efectos de determinados planes y programas en el medio ambiente.

Prosigue afirmando que "Aplicando la normativa expuesta al supuesto litigioso, el primer acto preparatorio formal no es anterior a 21 de julio de 2004, consta que la remisión de la documentación a la Consellería de Medio Ambiente es de 15 de diciembre de 2004. Por eso la normativa aplicable exigía someterlo a la evaluación ambiental estratégica".

A su vez, recuerda que la resolución de 24 de septiembre de 2014, de la Secretaría General de Calidad y Evaluación Ambiental, por la que se declara la 
inviabilidad de sometimiento del Plan General de Ordenación Municipal del Concello de Muxía al procedimiento de evaluación ambiental estratégica se dicta en respuesta a la solicitud del Concello de Muxía sobre declaración de inviabilidad del sometimiento a los trámites del Artículo 7 de la Ley 9/2006. Expone que la aprobación inicial del plan general es de 7 de junio de 2005 y la aprobación provisional de 28 de abril de 2007, y que "este tipo de declaración la permite el apartado 2 de la DT $1^{\underline{a}}$ de la Ley 9/2006, caso por caso y de forma motivada". Se remite a una resolución de 3 de marzo de 2008, de la Dirección General de Desarrollo Sostenible, que señala un conjunto de requisitos para poder declarar la inviabilidad de sometimiento del PGOM de Muxía a los trámites del Artículo 7 de la Ley 9/2006 y "como se cumplen las exigencias de la resolución de 3 de marzo de 2008, publicada en el DOG de 21 de abril de 2008, se declara la inviabilidad de sometimiento a la evaluación ambiental estratégica, si bien los planes especiales sí han de someterse a la misma cuando así lo decida el órgano ambiental en cada caso de forma motivada", añadiendo que "lo cierto es que solo se refiere a un ámbito. Y considera que el supuesto aquí analizado es diferente del tratado en las sentencias del Tribunal Supremo que cita la demanda".

A continuación, señala que "una cosa es que consideren que no hay vulneraciones a los valores ambientales protegidos, y otra que no haya de someterse por ello a la EAE, cuando admiten que son terrenos integrados en la Red Natura. No puede compartirse que por su sola clasificación, a efectos urbanísticos, se haya de llegar a la conclusión de que ya son objeto de protección integral, porque una cosa es la correcta clasificación del suelo de acuerdo con la normativa urbanística, y otra distinta que no se someta a EAE, sin que puedan las Administraciones demandadas determinar sin respetar la ley cuáles son los posibles riesgos medioambientales decidiendo en base solo a la clasificación del suelo qué es lo que ha de someterse o no a la EAE" y concluye que "si bien el requisito temporal se cumple para la obligación de la $\mathrm{EAE}$, lo que falta es la motivación para no someterlo".

Por todo lo expuesto, se estima el recurso, se declara la nulidad de la disposición general impugnada y se impone el pago de las costas procesales a la parte demandada y a la codemandada dentro del límite total de 1.500 euros. 
La última sentencia de este apartado es la 228/2018, de 7 de junio, de la Sección Segunda Sala de lo Contencioso del Tribunal Superior de Justicia de Galicia, que resuelve el recurso interpuesto en nombre y representación de "T" contra el Acuerdo del Concello de Pontevedra de 18 de abril de 2016 por el cual se aprobó definitivamente el Plan Especial de Infraestructuras y Dotaciones de la Calle Antón Fraguas de Pontevedra, en la Unidad de Actuación 35 del PGOM, tal y como recoge el Fundamento Jurídico Primero de la misma.

Es parte demandada el Ayuntamiento de Pontevedra, habiendo comparecido "C" en calidad de codemandada.

El Fundamento Jurídico Segundo contiene los fundamentos de la impugnación de la entidad recurrente, mientras que el Tercero los fundamentos de la oposición esgrimidos por el Ayuntamiento de Pontevedra.

En este sentido, "T" recuerda que el anterior Plan aprobado el 20 de julio de 2007, fue recurrido y anulado por la sentencia de 23 de junio de 2011 de esta misma Sala (confirmada además por el Tribunal Supremo) a causa de no haberlo sometido con carácter previo a la evaluación de impacto ambiental y hace hincapié en que el recurrido tampoco se sometió a la citada evaluación, a pesar de haber sido solicitada por el Ayuntamiento a la Xunta de Galicia, razón por la cual sostiene que incurre nuevamente en un vicio de legalidad que debe desembocar en su anulación.

La parte recurrente, "después de referir que con arreglo al Art. 5.d) de la Ley 6/2007 de medidas urgentes en materia de ordenación del territorio y del litoral de Galicia establece que serán objeto de evaluación ambiental estratégica los planes especiales cuando así lo decida el órgano ambiental en cada caso y que por Resolución de 11 de noviembre de 2014 del Secretario General de Calidad y Evaluación Ambiental se eximió a este Plan de someterse a los controles, entiende que tal decisión no está suficientemente motivada ni toma en consideración los criterios señalados en el Anexo II de la Ley 9/2006 de 28 de abril, sobre evaluación de determinados planes y programas en el medio ambiente (...)".

Alude posteriormente a jurisprudencia del Tribunal Supremo sobre anulación de Planes Generales por la omisión de la evaluación ambiental estratégica y 
termina solicitando "la anulación de la resolución recurrida, con los demás pronunciamientos que correspondan, con condena en costas de las partes que se opongan a la misma".

Por su parte, el Ayuntamiento de Pontevedra "después de señalar los precedentes de la situación y transcribir la St. 615/2011 de 23 de junio, de esta Sala, por la que se anuló el anterior PEID en base a que ni siquiera llegó a pedirse la evaluación ambiental y de referir los antecedentes de la tramitación que desembocaron en la resolución recurrida, (...) señala que, contrariamente a lo que se mantiene en la demanda, es la evaluación ambiental la que debe someterse a los criterios señalados en el Anexo II de la Ley 9/2006 y no la declaración de la exención".

Añade que "estamos en presencia de un proyecto ya ejecutado que diseña un aparcamiento público en suelo urbano consolidado en el Centro de Pontevedra, totalmente antropizado, de muy limitada superficie y que reducirá la presión de los automóviles en el contorno, suponiendo una mejora de las condiciones de la calle, sin que la recurrente alegue que suponga una mínima afección del medio ambiente".

A su vez, argumenta que este caso no tiene relación alguna con los acaecidos en las sentencias que invoca en la demanda y solicita la íntegra desestimación del recurso.

El Fundamento Jurídico Cuarto alude a la contestación de "C", donde indica que "la decisión de la exención de la evaluación se contiene en 6 folios, en las que se examinan las características del plan, las consideraciones jurídicas, las técnicas, y los efectos ambientales previsibles, por lo que mantiene que contiene una justificación y motivación, cumpliendo los criterios del Anexo II de la Ley 9/2006". Tampoco cree que resulte de aplicación al caso enjuiciado el criterio tomado en las sentencias referidas en la demanda, motivo por el cual solicita que se dicte sentencia desestimando el recurso, con expresa imposición de las costas procesales.

El Fundamento Jurídico Quinto ahonda en el fondo de la cuestión analizando la innecesariedad de la evaluación ambiental del Plan recurrido. En este sentido, 
indica que como advierte la recurrente "la cuestión suscitada en el presente recurso se limita a determinar si la motivación contenida en la resolución del Secretario General de Calidad y Evaluación Ambiental de la Xunta de Galicia, eximiéndolo de la evaluación ambiental, es o no ajustada a derecho".

Así, "de conformidad con el efecto propio de la cosa juzgada, la necesidad del trámite de la evaluación ambiental del Plan Especial resulta incuestionable, toda vez que, como todos admiten, el anterior Plan Especial fue anulado por omitir ese trámite que resulta preceptivo, pero ello no excluye que el mismo termine con la declaración de su innecesariedad".

Este fundamento añade que "Echa en falta la recurrente que ninguna de las consideraciones contenidas en la Resolución de la Conselleria resulta ajustada a las que habría de contener conforme al Anexo II, al que el Art. 5.1 letra d) de la Ley 6/2007, de 11 de mayo, de medidas urgentes en materia de ordenación del territorio y del litoral de Galicia, se remite".

El mencionado artículo estipula que los planes parciales, especiales y de sectorización tienen que ser sometidos a evaluación "cuando lo decida la administración autonómica, con la salvedad de que el Plan General, del que son desarrollo, ya hubiese sido sometido a la evaluación”. Cuando sea precisa la evaluación, es ella la que tiene que ajustarse a las exigencias del Anexo II de la Ley $9 / 2006$.

Esta conclusión también se infiere de los Artículos 3 y 4 de la Ley 9/2006 "ya que el primero condiciona el sometimiento a la evaluación ambiental de los planes y programas a que los mismos puedan tener efectos significativos sobre el medio ambiente, incluyendo incluso los que establezcan el uso de un reducido ámbito

territorial, pero en todo caso corresponde al órgano ambiental la determinación de sí un plan debe ser objeto de evaluación, pudiendo hacerlo bien caso por caso o en relación a un determinado tipo de planes o programas previamente especificados o mediante una combinación de ambos criterios, pero en todo caso atendiendo a los criterios del Anexo II".

Alude además a dos datos muy relevantes, "el primero, que la resolución dictada por la Secretaria Xeral, después de admitir que se trata de un proyecto que ya se llevó a cabo en el subsuelo de una vía pública, afirma que tuvo en 
cuenta los criterios establecidos en el anexo II de la Ley 9/2006 -que son a los que hay que atender- y, el segundo, que la entidad recurrente, después de transcribir los criterios para determinar la posible afectación sobre el medio ambiente contenidos en el referido anexo, no señala la más mínima probabilidad de afectación del medio ambiente como consecuencia de la aprobación del plan".

Por lo expuesto concluye que la resolución de la Consellería "explica razonablemente los criterios por los que entiende que el Plan no produce efectos significativos sobre el medio ambiente y decidió excluirlo de la evaluación, lo que determina la íntegra desestimación del recurso".

El Fundamento Jurídico Sexto se pronuncia sobre los precedentes invocados por la parte recurrente y su inaplicabilidad al supuesto que se está enjuiciando y concluye afirmando que "En el presente caso el Ayuntamiento de Pontevedra interesó la intervención del órgano ambiental y concluyó la innecesariedad de la evaluación, por resolución motivada y pública, por lo que el recurso, como dijimos, ha de ser desestimado" y como añade el Fundamento Jurídico Séptimo con imposición de costas a la parte recurrente, pero limitada a la cantidad máxima de $1.500 €$ para cada una de las partes demandadas. 